\title{
Strategy on Developing English Learning Material for Specific Purposes
}

\author{
Heryan Ardhi Kusuma ${ }^{1}$, Sigit Apriyanto ${ }^{2}$ \\ ${ }^{1}$ Madrasah Mu'allimin Muhammadiyah Yogyakarta, Indonesia \\ ${ }^{2}$ Faculty of Applied Science and Technology, Universiti Tun Hussein Onn Malaysia \\ 1.heryan290315@gmail.com, ${ }^{2}$ sigitteduh89@gmail.com
}

\begin{abstract}
(2.
Keyword:

Developing Material, Strategy,

ESP.

\section{ABSTRACT}

Teaching material is an important tool to achieve learning goals. Teaching materials can help teachers prepare learning activities, and guide students in learning, both at school and at home. Therefore, teaching materials must be prepared based on the basic principles and steps of the systematic development of teaching materials as well as the assessment criteria to use in the field to ensure the quality of teaching materials developed. This paper discusses developing learning material for ESP (English for Specific Purposes). The method used to describe the development of learning material is by conducting a qualitative in which the writer did the document review of some related articles and books. The discussion area about the definition, the principles, the procedures, and the practical undertaking of developing learning material for ESP. The development of teaching materials for creative and integrated English learning is an effort to facilitate student learning, moving from the old paradigm to the new paradigm. Hopefully, the main target of learning for them is not only the result of learning in the form of numbers, but the courage to show the ability through real action under the skills and knowledge mastered.
\end{abstract}

\section{Article History:}

Received: $13-10-2018$

Revised : 27-12-2018

Accepted: 29-12-2018

Online : $30-12-2018$

\section{(c) (1) (2)}

This is an open access article under the CC-BY-SA license

Crossret

https://doi.org/10.31764/ijeca.vli3.2144

\section{A. INTRODUCTION}

English is one of the compulsory subjects that should be learned by learners. The reason why it becomes a compulsory subject is because of its role in this globalization era. Every country in the world even needs English to be mastered since it is the international language used by most countries in the world. Moreover, some countries, especially Asia's Countries, are now facing the MEA in which people compete for each other to get the business market, job, and even the inter co-operation between countries around Asia.

In this case, English becomes a crucial thing to learn as early as possible. In Indonesia, especially, English is taught when learners are in the grade of Elementary school till they are in Senior High school. It aims to prepare qualified-English learners to face the upcoming period. Learners are taught in the contextualized topic to give them experiences in using English in their daily life. The four skills, Listening, Speaking, Reading, Writing, are integrated taught so that students will experience the integrated English learning process. 
In terms of the textbook at school, teachers usually use a/ some provided textbook/s which had been provided by the school. In this case, the textbooks were usually given or facilitated by the government in which teachers do not have a role to choose or select the textbooks. They only get it and use it in their teaching and learning process without having many possibilities to select the appropriate textbook suit to their students' needs (Hidayat et al., 2019). Because of the reason, the content of the material sometimes, even it often, does not suit the condition of the school, the students, and the school's curriculum, in some schools.

Moreover, by having a lack of opportunity to select the textbooks, it makes teachers difficult to adapt the content of the material to the student's prior knowledge. Briefly, it may affect the inappropriateness between the objectives of the learning made by teachers and the students' needs.

\section{Developing Materials}

Developing materials become a necessary thing should be conducted by the teacher to reach the learning objectives in which it can be reached by suit the learners' need and the material provided. Unfortunately, the importance of material development is rarely considered by them. To have good developing material, teachers need to know and understand the definition of the material itself, so that the material can help teachers in delivering the topic. Meganathan (2008) stated that materials are any systematic description of the techniques and exercises to be used in classroom teaching.

Material is used by the teacher to supplement classroom instruction or to stimulate the interest of students. A textbook, a workbook, worksheet, a cassette, a video, a paper, journal article, or something like a written paragraph on the whiteboard can be used as material as long as it presents and informs the language being learned as Tomlinson (1998) also defined material as anything which can be used to provide and facilitate the language learning. The material developed can be; 1 ) instructional material in which the material informs the learners about the language, 2) Experiential material in which material provides a chance to learners to exposure the language in the use, 3) elicitation material in which the material stimulates the use of the language, or 4) Exploratory material in which it gives a chance to learners to discoveries about the use of language in natural settings.

However, in developing the materials, the developer should elaborate on the two necessary things. Those things are the field of study and a practical undertaking. The field of the study explains the principle and procedures in designing the material, the implementation, and also the evaluation of the materials developed. Besides, the practical undertaking correlates with production, evaluation, and adaptation of language teaching materials. In this paper, there will be a discussion of the material development by considering the principles and procedures of the material development through evaluating, adapting, supplementing, and creating own materials (Pinter, 2006).

\section{Material Development as a field of study}

In this case, material development explains the principle and procedures of the design, implementation, and evaluation of the material.

\section{Principles of Materials Development}

One thing needs to consider before developing the material is the principles of materials development. Here are the principles stated by Richards (2001): 
1. The material must be based on sound theoretical learning principles

The learning principle, especially in language learning, that can be understood by the teacher is that there is an instructional activity in which involves the language skills required. It also should have an aim to reach and achieve language learning.

2. The material must arouse and maintain learners' interest and attention.

To arouse the learners' interest in learning the material, relevant material is needed. Relevant material will help the learners understand the topics easily and of course, providing the relevant material will increase students' motivation and give a chance to get the learning more effective (Wesche, 2012).

In other words, the material should achieve an impact. The indicator that material achieves the impact is by looking at whether the material has a noticeable effect or not. If learners have curiosity, interest, and attention to the material, it can be said that the materials have an impact.

3. Meet the learners' need and background

Materials should take any attention into the learners' need since it becomes the important thing should be considered before the development. The learners need can be obtained by asking the teacher or conducting the observation. It can be also done by looking at the syllabus used. In addition to learners' background, learners have different learning styles in which it needs teachers' awareness in the development of the material. The learning style here includes visual, audio, kinesthetic, etc.

In this case, one student may have a visual learning style in which they prefer to see the content material to listen to the material. Furthermore, the student may have an auditory learning style in which they prefer to listen to the material to see the object or do something. On the other hand, some students may have kinesthetic learning styles in which they prefer to do something physically to listen or see the material.

4. Provide examples of language use

A good material should give many examples of language use. Learners will get the ease of the learning language if they are given more examples of the use of the language which relevant to their life. The examples can be in the form of texts and illustrations which closely happened around the learners' life.

5. Provide meaningful activities

Meaningful activities mean that the activities will give learners a real experience in using the language so that they can get the meaning of learning the language. The activities may come from the instruction and task that require students to do something physically by using the context of language use. The material should not be only explaining without considering the activities the learners can do.

6. Provide opportunities for authentic language use

According to Tomlinson (2010), the material should espouse the learners to language in authentic use. It can be made by providing instructions or advice that lead to the exposure of the language and by providing a spoken and written text included in the materials. Giving many opportunities to students will give them much experience to see and know in what condition the language is used. The language use here should be authentic in which learners may often find in their daily life. 


\section{Materials Development Procedures}

The steps or procedure of materials development includes the design, implementation, and evaluation of language teaching materials. Specifically, the steps of developing materials are; 1) Field survey, 2) Analysis of data and identifying priority needs, 3) Selection of theme, 4) Selection of format,5) Selection of content, 6) Writing, illustrating and editing the material, 7) Pre-testing of draft material, 8) Revision of draft material and preparation for printing, 9) Printing, 10) Evaluation. All of the steps need to be systematically passed to get a good and suitable material development.

Briefly, the teaching/learning material is made starting from designing the material by considering the need for analysis and learning needs. After that, the material already developed for specific target learners must be applied in the real learning/teaching situation. It is done to try out the material if it is suitable or not for the learners. Also, if the material is not suitable, then it must be revised before it is printed and produced. The revision here is the evaluation step that must be passed by the developer.

\section{Materials Development as a Practical Understanding}

In practice, As Pinter (2006) said that the development of the teaching and learning material can be done by evaluating learning materials provided, adapting, supplementing, and creating own material. The way how to evaluate the material is usually done by teachers by observing the content whether it works or doesn't work for students. It can be interpreted by teachers by considering the context of the materials and the learner's need. Teachers usually know which one is suitable for their students and which other is not suitable. Teachers know the learners' needs since they have taught the learners or by looking at the syllabus and learning objectives they made. Moreover, another way to evaluate the material is by exploring the teacher's and learner's experience and also opinion during they use the material in the classroom. However, the result of this evaluation may be not valid for different students and at different times.

After evaluating the material, or textbook, teachers have their own decision to use the material provided, or adapt it by considering the learners' need. Moreover, teachers can also supplement the material if they think it's necessary or even they can change all of the material, create it by their material if they think that the provided material doesn't fulfill the teacher's criteria by considering the learners' need. Adapting the material is different from adopting the material. In this term, adopting does not need further action to develop the material, while adapting there should be further action before using the material. In adapting, the main thing needs to understand by the developer is that it must be from the clear source and must be suitable to learner's need in term of their level of study and background.

Pinter (2006) explain the adaptation of a fable entitle "The Grasshopper and the ants". The topic is different from the original one since his suit the material to the students' need. However, it still becomes a good material for his students because there is a learning process of new vocabulary, structures, and functions. Something needs to remember in adapting the material is that adapting an authentic material doesn't always run well. Teachers need to remember the English learning that learners must learn from the adapted material. Moreover, we still need to allow the learners to get more challenge from the material adapted.

Supplementing the provided material is another way to solve the weakness of the available material. The material in which is not suitable to the syllabus, curriculum, or learners' needs can be supplemented by materials made by the teacher to make it match the learning objectives and achieving communicative competence in English (Anum \& Apriyanto, 2019). Of course, it needs teacher creativity to supplement the materials. However, it can solve the problem of the 
inappropriateness of the material. If supplementing materials does not meet the need of learning objectives, teachers must create their materials. It is the last effort teachers can do to provide suitable material.

In creating own material, there are some fundamental thing need to remember by teachers. Those fundamental bases are the learning objectives or instructional materials, learners' needs, and topic-based planning (Pinter, 2006). Dick et al., (1985) said that he suggested a long procedure to develop the instructional material in which the instructional material was made after identifying the instructional goals. At least, five steps are needed to pass to develop instructional material. Those steps are: 1) Conducting instructional analysis, identifying learners' behavior and characteristics, writing performance objectivism developing criterion-referenced test items, and developing instructional strategy. After conducting those steps, the next step is developing instructional material itself. Dick and Carey emphasize the accuracy of all the components in the system approach of instructional design.

Learning material can be also developed by teachers based on the learners' needs (Pinter, 2006). Teachers can find out the learners' needs first by observing the students' competence and also the learning objective that the students' are required to achieve. After knowing the needs, teachers start to develop the material to help students achieve the learning objectives or their competence. Furthermore, teachers can also develop the material based on the "Topic-based planning" which means that all materials should be based on the topics that have been decided and chosen. In this case, the material should provide activities related to the chosen topic. Even, all the activities in the Curriculum should be related to that topic.

\section{B. METHODS}

A descriptive qualitative method was used by the researcher for this study. According to Hancock (see Elliott \& Timulak, 2015)., qualitative research is concerned with developing explanations of social phenomena. It aims to help the researcher to understand the social world and why things are the way they are. Hancock believes that it is concerned with the social aspects of the world and seeks to answer questions about 1) Why people behave the way they do, 2) How opinions and attitudes are formed. 3) How people are affected by the events that go on around them. 4) How and why cultures and practices have developed in the way they have. The researcher conducted a document review to gather the data. The objects of the research are two existing articles mainly discussed the learning and teaching development. After that, the data are interpreted qualitatively to describe the result.

\section{RESULT AND DISCUSSION}

\section{Developing English Learning Materials for Specific Purposes}

Here, the principles and procedures of developing material will be implemented in the case of developing English learning material for specific purposes. Because this is the material for specific purposes, there are some things should be considered by the developer before they develop the material. As explained above that learners' need is becoming one of considerable thing in developing the material, in developing material for specific purposes it even become the first thing should do. Developing a kind of material may be useful for some cases, however, it may also become useful if it is used in another case. Say for example, when the teacher makes material for teacher-training students, it will be useful for them since it is 
developed for them. However, it will be useful if it is implemented for nursing students. Briefly, every specific purpose has different characteristics and learners' needs as well. Hutchinson \& Waters (1989) stated that English for specific purposes is based on designing courses to meet learners' needs.

To know the learners' needs, the teachers or material developers can identify the learning objectives formulated by the institution or the teacher itself. The learning objectives here also can be identified in the form of the syllabus. The syllabus is a document that says what will be learned (Hutchinson \& Waters, 1989). From the definition, we may conclude that the learning objectives are explicitly explained in the syllabus.

To design the material, Hutchinson \& Waters (1989) proposed four approaches including a language-centered approach, a skills-centered approach, and the pst hoc approach. To design the material using the language-centered approach, there are five steps should be conducted by the developer; 1)analyzing target situation, 2) writing syllabus, 3) writing or selecting texts to illustrate the item in the syllabus, writing exercises to practice items in the syllabus, and devising a test for assessing knowledge of the items in the syllabus. In a skills-centered approach, The steps should be done by teachers or developers are analyzing target needs, selecting interesting texts, devising the hierarchy of the skill to exploit the texts, ordering or may adapting the necessary material to focus on the skill involved, devising the technique to teach those skills and devising system to assess the acquisition of the skills. In a learning centered-approach, the procedures should be considered are: (1) analyzing learning situation, creating interesting and enjoyable materials, and checking language and skills content of materials and making necessary adjustments; (2) analyzing target situations, establishing general syllabus of topics and tasks, creating interesting and enjoyable materials, and checking language and skills content of materials and making necessary adjustments; (3) analyzing target situations, establishing general syllabus of topics and tasks, producing detailed language/skills syllabus, and checking language and skills content of materials and making necessary adjustments. In the post hoc approach, there are only two steps in the procedure: writing materials on undefined criteria and writing cosmetic syllabus to make sponsors, teachers, students, satisfied.

After designing the draft of the material, the next step is developing the material. In this case, teachers or developers should follow the procedure in developing a kind of material. Firstly, as explained in the steps of design, we can assume that the first thing need to do by teachers is knowing the learners' need. After deciding and knowing the learners' needs, the development of the material should be suitable for the principles and also the procedures of the development of the material. However, the nature of the learning material should be also considered by teachers to achieve language learning objectives. Like the learning language, teachers need to be able to differentiate the materials in terms of content and language. Briefly, the teacher can use the existing material if it is suitable. If it is not suitable, the teacher should develop their material.

Considering the principles of developing the materials, the teachers can use one or more principles of developing the material. As explained in the previous discussion, one of the principles that should be considered by the teacher in developing the material is "Material must arouse and maintain learners' interest and attention" (Richards, 2001). The material that will be developed should have a characteristic of arising learners' interest and motivation so that the learners have a more willingness to learn the material. To develop this material, the teachers or developers can make an activity which gives an illustration in one 
context that learners often find in their daily activity life. It can be also created by making a presentation using an interactive way including nice colors, or by providing the authentic topic which is interested in most learners. Briefly, the material should give an impact on students or learners.

That is also the answer to why teachers need to know the students' needs and backgrounds. Knowing the students' needs and the background will help teachers or developers in developing the topic, so that it will be suitable to students' prior knowledge and background and help them to create an interest material in which it can help the teacher to achieve the learning objectives. Suitable to students' need is also one of the principles need to fulfill by teachers and developers in developing material as stated by Richards.

In dealing with the procedures in developing the materials, there are steps need to fulfill by teachers. Those steps are designing, implementing, and evaluating. Those steps should be conducted to produce more accurate and appropriate learning material. In the design step, teachers or developers need to analyze the students' needs and sometimes syllabus by considering the principles of developing material. After they analyze and make a design and the draft, the teachers need to implement the design or the draft. The design and the draft must be implemented to learners in the real teaching and learning process. If there is a weakness in the material developed, the teachers need to revise the materials. The revision can be conducted more than once depending on the result of the tryout. This is what we call the evaluation step.

\section{Steps in Developing Teaching Materials}

The development of teaching materials, including English teaching materials, is an activity in the Research and Development (R\&D) category (Hatch \& Lazaraton, 1991). Hedge (2002)suggested 10 steps that must be taken in developing products for learning. But Gall et al., (2003), which uses the Cunningham research model, simplify the development process into six steps, namely:

1. Review relevant libraries about the textbook to be written.

2. Plan the objectives of each chapter or section.

3. Develop an initial draft.

4. Conduct a trial of the initial draft on a limited number of subjects.

5. Revise the initial draft based on the results of the trial.

6. Re-examine the revised draft based on the results of the first trial on a larger number of subjects

Literature studies include the study of development theories, learning theories (for example various learning methods that are suitable with the material being developed) (see Radwan, 1990), ideal textbooks (according to textbook assessment guidelines) (see Anthony, 1997), the reality of textbooks on the market or those that are tangibly used in schools. By looking at the teaching material available and understanding of the ideal material, the compiler of the teaching material will have a picture of what teaching material should be arranged to close the gap so that the learning objectives of English can be achieved.

After obtaining an overview of what will be written, the compiler of the teaching material must plan the overall objectives of the teaching material and set goals for each chapter or section. In the context of writing English teaching materials for junior high school, the compiler of the material must look at the syllabus for the relevant class and semester (Davies, 2008). It is regulated that in each semester there are competency standards with basic competencies to be achieved, complete with the type of text that must be studied in the 
semester. Thus, any form of teaching material must support the achievement of the basic competencies that have been announced during the semester. Whether or not a basic competency is achieved will be determined by teaching materials arranged according to the objectives in each chapter/section.

Based on the objectives that have been compiled, the compiler teaching material seeks to develop the initial draft. What needs to be considered, to be more meaningful and easily tested for their usefulness, teaching material should have reflected the steps of activities that demand an understanding of certain linguistic aspects and the use of skills in real situations according to the specified learning objectives (Sze-yeng, 2013). By looking at the draft material and how it is presented, material and learning experts will easily provide input (input) improvements or determine the feasibility / improper teaching material that has been prepared. The next stage after the initial draft is arranged is limited field trials, in the sense of the number of schools/classes and students. Before field trials are carried out, it would be very beneficial if the draft material can be checked in advance by the material and learning experts. Although Gall et al., (2003) do not recommend this step, an examination of the initial draft by the material and learning expert can reduce the weaknesses that exist, especially in the linguistic and presentation aspects. Mistakes in linguistic aspects can hurt students and teachers. If the error is vague, for example in the use of prepositions (prepositions), the less careful teacher may not recognize or hesitate to determine whether or not the error occurred.

\section{Basic Principles of Teaching Materials Development}

It has been mentioned in the previous section that the purpose of preparing English teaching materials is to facilitate teachers and students in the learning process. To achieve this goal, Tomlinson (1998) presents the basic principles of acquisition of a second language that is relevant to the development of the material. Teaching material that is compiled should:

1. have a positive impact,

2. make students feel comfortable,

3. help students develop self-confidence,

4. students are seen as something relevant and useful,

5. make students willing to try because they feel the benefits,

6. following the readiness or provision that students have,

7. contains language features that should be of concern to students,

8. allows students to use English to achieve communicative goals,

9. consider students' differences in learning styles and their affective traits,

10. consider the possibility of silence (students may not be forced to speak) at the beginning of the learning period, and

11. Maximizing the various potentials of students by involving intellectual, aesthetic, and emotional intelligence which can stimulate right-brain and left-brain activities.

In addition to the above 11 points, other principles can be added, such as the principle of collaboration between students, the principle of developing independence, the principle of entrepreneurship, the principle of diversity, etc. Among these principles is part of the criteria used to assess the feasibility of textbooks (BTP) by the Ministry of National Education. 


\section{CONCLUSION AND SUGGESTIONS}

Developing an instructional material becomes a compulsory thing that should be considered, even do, by the teacher to improve the teaching and learning quality. Some existing topic, sometimes, is not appropriate to students' knowledge background, the context, and even the curriculum of the school. So, developing a kind of material will become an alternative way to solve the inappropriateness.

In developing learning material, some considerable things should be understood by the developer. The principle and the procedures become the two things that should be remembered by the teachers or developers before developing the topics. The principles need to remember to create a theoretical learning material so that the material can be suitable and appropriate to the principle of learning material. Besides, the procedures also become the second thing that needs to remember since it will affect the result of the developed material. The material will e accurate if the teacher did all of the procedures or the steps in developing the material.

The need analysis as one of the steps in developing the materials will be the one that should be considered since it will affect the content and the quality of the material. Briefly, an appropriate and eligible requirements of the material will depend on the need analysis as the first thing the developer do before. Also, the stages in developing the materials should be considered and done by the developer. The main stages of developing were designing, implementing, and Evaluating. If the developer passed these three stages, it will be good and it will be valid to use. In developing the materials, the try out will be important as well as the learned need analysis since it will affect whether our content is necessary to revise. If the developed material needs to review, then the speakers need to revise. This is the step of evaluation.

Develop teaching materials not only collects the material to develop the knowledge development of teaching materials should be viewed as a design activity or learning experience. Thus the compiler of teaching materials must pay attention to the basic principles of material development according to the chosen learning method, systematic development steps, and follow standardized assessment criteria. Thus, the evaluation through testing the material has a clear reference, so that input from the evaluator is easy to provide and revisions will also be easy to do.

\section{ACKNOWLEDGEMENT}

Thanks for The Almighty Allah SWT for all of His blessings so that I can finish this paper. In the process of finishing this paper, support and motivation are much given to me. Therefore, I would like to thank those who have supported and encouraged me to finish and accomplishing this paper. Honestly, I realize that without their support and role, this paper would not be completed. Of course, I would like to express thanks to my wife who always gives her the best support and all of my graduate classmates.

\section{REFERENCES}

Anthony, L. (1997). Defining English for specific purposes and the role of the ESP practitioner. Retrieved November, 18, 2008.

Anum, A., \& Apriyanto, S. (2019). Detecting Gender'S Strategies in Learning Speaking. Premise: Journal of English Education, 8(1), 57.

Davies, A. (2008). An introduction to applied linguistics. From practice to theory (2nd edition). English for 
Specific Purposes, 27(3), 363-367.

Dick, W., Carey, L., Glenview, \& Scott, F. (1985). The systematic design of instruction. Performance and Instruction Journal, 24(October), 13.

Elliott, R., \& Timulak, L. (2015). Descriptive and interpretive approaches to qualitative research. In J. M. and P. Gilbert (Ed.), A Handbook of Research Methods for Clinical and Health Psychology (pp. 147157). Oxford University Press.

Gall, M. D., Gall, J. P., \& Borg, W. R. (2003). Epdf.Pub_Educational-Research-an-Introduction-7Th-Edition.Pdf.

Hatch, E., \& Lazaraton, A. (1991). Design and Statistics for Applied Linguistics. Heinle \& Heinle Publisher.

Hedge, T. (2002). Teaching and Learning in the Language Classroom. T. Hedge. ELT Journal, 56(3), 337341.

Hidayat, O., Apriyanto, S., Program, P., Science, A., Tun, U., \& Onn, H. (2019). Drama Excerpt: Tool in Enhancing Speaking Ability for Junior High School. 2(3), 1-9.

Hutchinson, T., \& Waters, A. (1989). English for Specific Purposes: A learning-centred approach. Cambridge University Press.

Meganathan, R. (2008). Materials Development in English as a Second Language: An Indian Experience. Online Submission, 12(2), 3-8.

Pinter, A. (2006). Teaching Young Language Learners. Oxford University Press.

Radwan, A. A. (1990). Effects of L2 proficiency and gender on choice of language learning strategies by university students majoring in English. Asian EFL Journal, 115-163.

Richards, J. C. (2001). Curriculum Development in Language Teaching. Curriculum Development in Language Teaching, 33(2), 107-109.

Sze-yeng, F. (2013). Self-direction Learning in An E-Socioconstuctivist Learning Environment. University of Malaya.

Tomlinson, B. (1998). Materials Development in Language Teaching. Cambridge University Press.

Tomlinson, Brian. (2010). Principles and procedures of materials development for language learning: 3 Proposals for principled approaches to the development of ELT materials. Materials in ELT: Theory and Practice, 1995.

Wesche, M. B. (2012). Content-Based Second Language Instruction. The Oxford Handbook of Applied Linguistics, (2 Ed.), May 2018, 1-22. 